\title{
Bronchoscopic extraction of multiple endobronchial broncholiths in a patient with active pulmonary tuberculosis
}

\begin{abstract}
Broncholithiasis is an unusual clinical condition characterized by the presence of calcified or ossified material within the airways. Multiple endobronchial broncholithiasis during active infection with tuberculosis is an extremely uncommon presentation. Bronchoscopy plays an important role in the diagnosis and management of broncholithiasis. Currently, there are no specific guidelines for the management of broncholithiasis. Here, we present a case report where multiple broncholiths were successfully removed in a staged manner via rigid bronchoscopy.
\end{abstract}

Key words: broncholiths, broncholithiasis, rigid bronchoscopy, flexible bronchoscopy, lithoptysis

Adv Respir Med. 2021; 89: 520-523

\section{Introduction}

The term broncholithiasis is used to denote the presence of calcified or ossified material within the bronchial lumen [1]. It is an unusual condition with an incidence of only $0.1-0.2 \%$ of all lung diseases [2]. Though calcification is often seen in chest imaging as a sequelae of mycobacterial, fungal granulomatous lymphadenitis and silicosis, symptomatic endobronchial broncholithiasis is uncommon [1]. Broncholiths are calcified peribronchial lymph nodes which usually impinge on the bronchus or erode into the airway lumen [3]. Broncholiths can be detected incidentally during routine bronchoscopy or during evaluation of hemoptysis, cough, or recurrent pneumonia. Asymptomatic patients can be managed conservatively, whereas surgical or bronchoscopic removal is required for symptomatic patients [2].

Broncholiths have been removed successfully using forceps, laser photocoagulation, or cryotherapy $[4,5]$. Here, we present a case report about the successful bronchoscopic removal of multiple broncholiths in a staged manner via rigid bronchoscopy. Multiple endobronchial broncholithiasis during active infection with tuberculosis is an extremely uncommon clinical presentation. Bronchoscopy plays an important role in its management.

\section{Case history}

A 63-year man who had never smoked presented with progressive dry cough and dyspnea of six months duration. He also had low grade fever (sometimes reaching $101^{\circ} \mathrm{F}$ ) for about a month. There was no chest pain, hemoptysis, or loss of weight or appetite. He did not have a history of infection with tuberculosis. He did not have any other comorbid conditions. At presentation, he was afebrile and tachypneic. Auscultation revealed decreased air entry in the left chest. His chest radiograph showed a left lung midzone consolidation with multiple calcified densities in bilateral paratracheal and parabronchial regions (Figure 1A). Contrast-enhanced computed tomography (CECT) of the chest showed bilateral areas of patchy consolidation (Figure 1B) with multiple calcified lymph nodes in pre-paratracheal, pre-vascular, subcarinal and right hilar regions (Figure 1C). There were also calcified nodes in the 

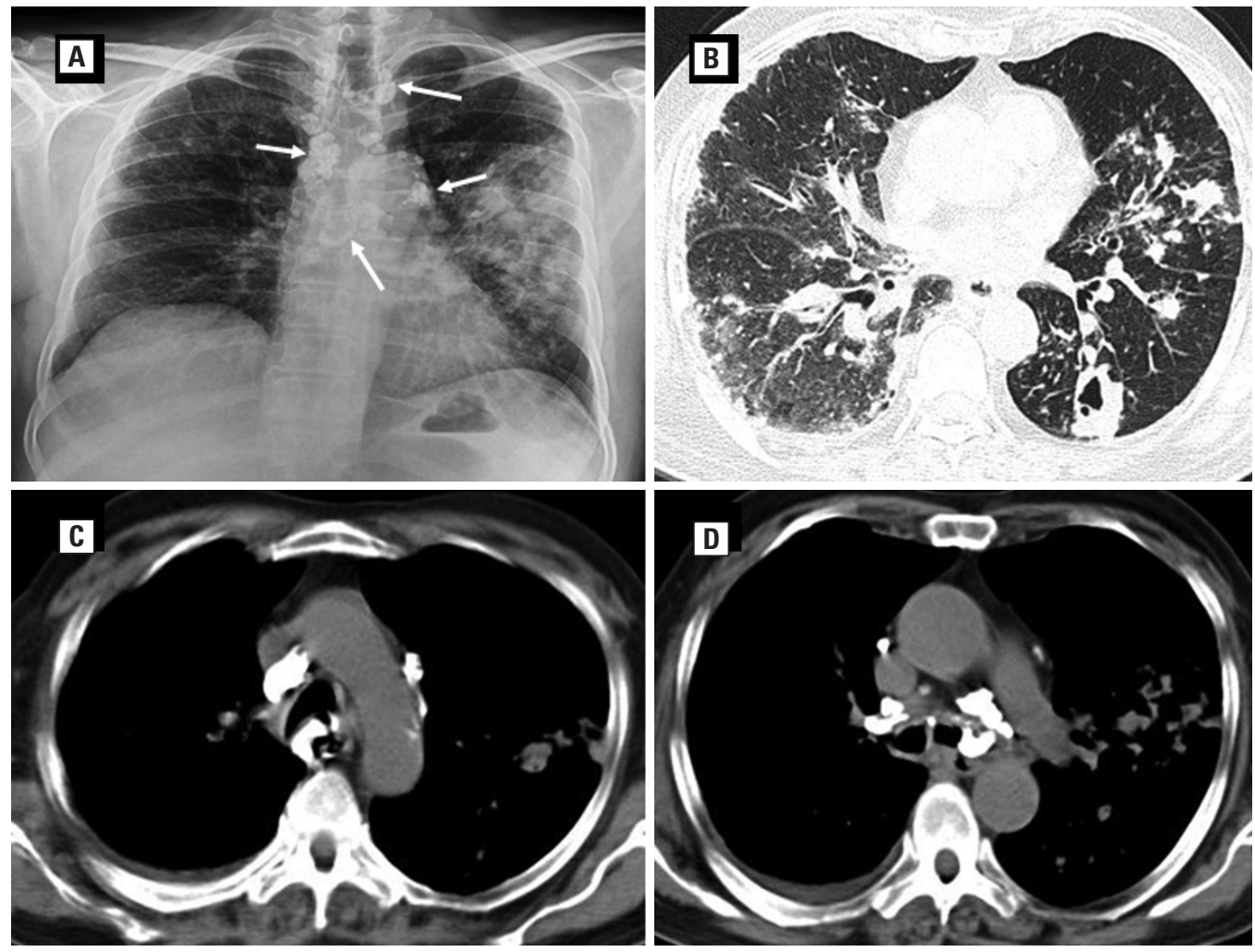

Figure 1. A. Chest radiograph showing multiple calcified opacities (broncholiths) in the paratracheal and peribronchial locations (white arrows) and a large patch of consolidation in the left mid zone; B. Lung parenchymal window of computed tomography (CT) of the chest showing multifocal patchy consolidation and cavities in bilateral lung fields; C. Mediastinal window of CT of the chest showing calcified subcarinal, paratracheal and para-aortic nodes in the mediastinum (extraluminal broncholiths); D. Mediastinal window showing an intraluminal broncholith in the left main bronchus as well as extraluminal broncholiths adjacent to both main bronchi

lumen of the left main bronchus (LMB) (Figure 1D). Bronchoscopy revealed edematous mucosa, granulation tissue, and two broncholiths occluding the lumen of the LMB (Figure 2A). Bronchial washings were positive for acid fast bacilli (AFB) on smear and gene Xpert MTB/Rif.

Rigid bronchoscopy was performed in order to remove the broncholiths. Under general anesthesia, the patient was intubated using a rigid tracheobronchoscope (Efer Dumon series III, $13 \mathrm{~mm}$ OD) The proximal granulation tissue was removed using a flexible cryoprobe (Erbe cryoprobe, $1.9 \mathrm{~mm}$ OD), and then the broncholiths were crushed with rigid forceps and removed piecemeal (as the broncholiths could not be removed in-toto). However, all broncholiths could not be removed in the first sitting. Post-procedure, the air entry to the left lung improved and the patient was started on anti-tubercular therapy (ATT). The patient spontaneously coughed out three broncholiths (lithoptysis) in the following month. Repeat bronchoscopy showed one residual broncholith causing partial occlusion of the LMB (Figure 2B). There was also a fistulous tract seen arising from the proximal left main bronchus and ending in the subcutaneous plane near the xiphisternum (broncho-subcutaneous fistula). In the second session, an entire broncholith was removed en masse using rigid forceps via the rigid bronchoscope. There was significant improvement in cough and breathlessness following the procedure. The patient is currently improving on ATT and repeat bronchoscopy showed no recurrence of endobronchial broncholiths (Figure 2C).

\section{Discussion}

Broncholiths are classified into two groups based on their origin: a) Intrinsic calculi, developed from lungs, bronchi, and lymph nodes; b) extrinsic calculi, developed from aspirated foreign bodies, secretions, and dusts. Broncholiths are usually gray-white and variable in size and shape with spur like projections or sharp edges. The chemical composition is of calcium phosphate (85-90\%) or calcium carbonate (10-15\%) [1]. The broncholiths are also classified based on their location in the tracheobronchial 

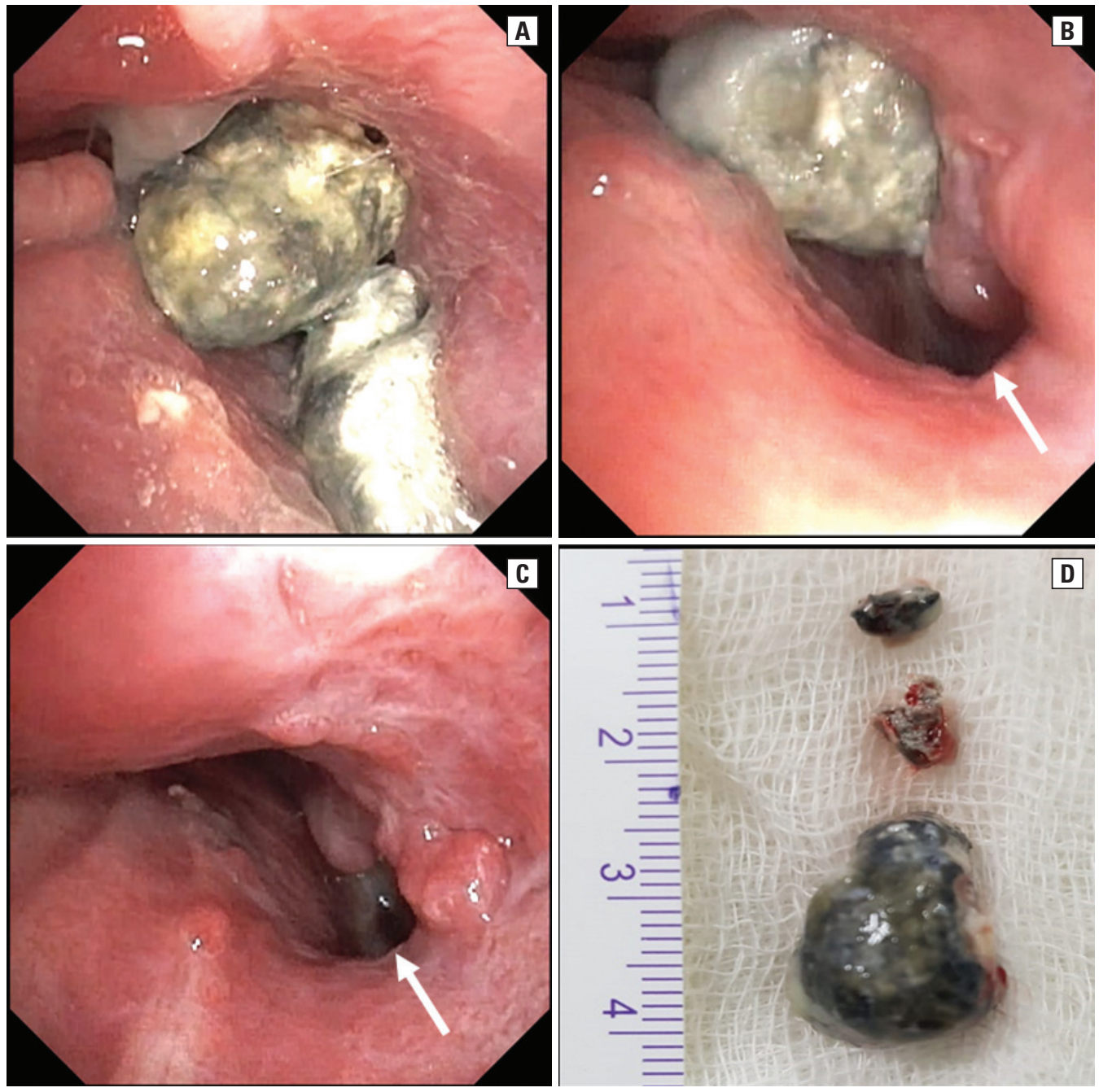

Figure 2. A. Bronchoscopic image showing two large broncholiths occluding the left main bronchus; B. Repeat bronchoscopy done after removal of one broncholith showing a fistulous opening, bronchial end of the bronchocutaneous fistula (white arrow); C. Image after removal of all intraluminal broncholiths; D. Broncholith after rigid bronchoscopic extraction

tree and can be intrabronchial, transbronchial, or extrabronchial [6]. The pathogenesis of broncholith formation can be explained by multiple mechanisms. A chronic long-standing infection or inflammation, usually of granulomatous etiology, brings calcium into airway walls or into adjacent lymph nodes. A calcified bronchial cartilage or a calcified necrotic lymph node then erodes into airways causing broncholiths. Another mechanism has been proposed to explain the presence of broncholiths without airway erosion/fistula formation. A necrotic/caseating lymph node discharges its contents in a liquid form into the bronchus and this caseating material calcifies on exposure to air leading to broncholith formation [1].

Broncholiths, by causing endobronchial obstruction, can lead to recurrent post-obstructive pneumonia and lung abscess formation [7]. They can also erode into airways causing fistulae and hemoptysis [8, 9]. Occasionally, they can be expectorated spontaneously leading to resolution of symptoms [10]. Most patients with broncholiths have a past history of tuberculosis, silicosis, or histoplasmosis. Occurrence of broncholithiasis during the acute phase of tuberculosis is less common, as was seen in the index case [11].

Treatment options include observation for asymptomatic cases, and bronchoscopic removal (flexible or rigid) or surgery in symptomatic cases depending on local expertise and resources $[3,12$, 13]. With increasing experience in therapeutic bronchoscopy, most centers now recommend bronchoscopic extraction as the initial modality of therapy for patients with symptomatic endobronchial broncholithiasis [1]. Surgical removal is considered in cases of symptomatic purely extrabronchial broncholiths, fixed broncholiths 
(when bronchoscopy fails), or when there are complications like massive hemoptysis and/or broncho-esophageal fistulae [3].

Various bronchoscopic methods have been described for the removal of broncholiths. Forceps, laser photocoagulation, and cryoprobe extraction have all been shown to help in extracting broncholiths $[4,14]$. Laser-assisted broncholithotripsy has also been described for removing impacted broncholiths [15]. Flexible bronchoscopic removal appears favorable in cases with loose or partially eroded broncholiths [13]. Rigid bronchoscopy is preferred over flexible bronchoscopy in cases of symptomatic large or fixed broncholiths. The size and location of the broncholith, mobility, relation to surrounding vascular structures, and distal parenchymal pathology impact the decision on which modality to choose. Cerfolio et al. presented an algorithm for the management of broncholiths based on symptomology and relationship of the broncholith to the airway (extrabronchial versus endobronchial, fixed vs mobile) [3].

The ability of the clinician to choose wisely using a combination of both rigid and flexible bronchoscopes along with various accessories like forceps, cryotherapy, or lasers is essential for a successful outcome. It is always recommended to have a thoracic surgeon on standby before attempting broncholith removal.

\section{Conclusions}

Multiple endobronchial broncholiths during active tuberculosis is an uncommon clinical presentation. Bronchoscopy plays an important role in the diagnosis and management of broncholithiasis. Rigid bronchoscopic removal of symptomatic broncholiths is a feasible and safe option. When bronchoscopic removal fails, surgical extraction remains the treatment of choice.

\section{Conflict of interest}

None declared.

\section{References:}

1. Alshabani K, Ghosh S, Arrossi AV, et al. Broncholithiasis: A review. Chest. 2019; 156(3): 445-455, doi: 10.1016/j. chest.2019.05.012, indexed in Pubmed: 31173766.

2. Anwer M, Venkatram S. Broncholithiasis: "incidental finding during bronchoscopy"-case reports and review of the literature. J Bronchology Interv Pulmonol. 2011; 18(2): 181-183, doi: 10.1097/LBR.0b013e31821810ea, indexed in Pubmed: 23169093.

3. Cerfolio RJ, Bryant AS, Maniscalco L. Rigid bronchoscopy and surgical resection for broncholithiasis and calcified mediastinal lymph nodes. J Thorac Cardiovasc Surg. 2008; 136(1): 186-190, doi: 10.1016/j.jtcvs.2007.09.084, indexed in Pubmed: 18603074.

4. Campbell SN, Lala D, Rubio E. Cryotherapy: A viable tool to remove broncholiths under flexible bronchoscopy. Biomedicine (Taipei). 2016; 6(4): 24, doi: 10.7603/s40681-016-0024-2, indexed in Pubmed: 27848115.

5. Go T, Kobayashi H, Takata M, et al. Endoscopic management for broncholithiasis with bronchoesophageal fistula. Ann Thorac Surg. 2007; 84(6): 2093-2095, doi: 10.1016/j.athoracsur.2007.06.071, indexed in Pubmed: 18036946.

6. Lim SoY, Lee KJ, Jeon K, et al. Classification of broncholiths and clinical outcomes. Respirology. 2013; 18(4): 637-642, doi: 10.1111/resp.12060, indexed in Pubmed: 23356409.

7. Summers SM. Broncholithiasis with post-obstructive pneumonia and empyema. J Emerg Med. 2013; 45(4): 612-614, doi: 10.1016/j.jemermed.2013.01.039, indexed in Pubmed: $\underline{23664715}$.

8. Wiese TA. Mainstem to mainstem bronchial fistula from broncholithiasis. J Bronchology Interv Pulmonol. 2012; 19(1): 7880, doi: 10.1097/LBR.0b013e3182425532, indexed in Pubmed: $\underline{23207272 .}$.

9. Ford MAP, Mueller PS, Morgenthaler TI. Bronchoesophageal fistula due to broncholithiasis: a case series. Respir Med. 2005; 99(7): 830-835, doi: 10.1016/j.rmed.2004.12.004, indexed in Pubmed: 15893922.

10. Ozyurek BA, Bozbas SS. Broncholithiasis presenting with lithoptysis. Lung India. 2018; 35(4): 339-340, doi: 10.4103/ lungindia.lungindia_304_17, indexed in Pubmed: 29970776.

11. WALSH JJ. Broncholithiasis; report of a case occurring in active pulmonary tuberculosis. Dis Chest. 1954; 26(2): 235-238, indexed in Pubmed: 13182967.

12. Jin YX, Jiang GN, Jiang L, et al. Diagnosis and treatment evaluation of 48 cases of broncholithiasis. Thorac Cardiovasc Surg. 2016; 64(5): 450-455, doi: 10.1055/s-0034-1395388, indexed in Pubmed: 25463358.

13. Olson EJ, Utz JP, Prakash UB. Therapeutic bronchoscopy in broncholithiasis. Am J Respir Crit Care Med. 1999; 160(3): 766-770, doi: 10.1164/ajrccm.160.3.9810021, indexed in Pubmed: 10471594.

14. Krishnan S, Kniese CM, Mankins M, et al. Management of broncholithiasis. J Thorac Dis. 2018; 10(Suppl 28): S3419S3427, doi: 10.21037/jtd.2018.07.15, indexed in Pubmed: $\underline{30505529}$.

15. Aust M, Prakash U, McDougall J, et al. Bronchoscopic broncholithotripsy. Journal of Bronchology. 1994; 1(1): 37-41, doi: 10.1097/00128594-199401000-00011. 